\title{
Del discurso narrativo al discurso teatral: selección léxica en Cervantes y Tirso*
}

\author{
CRISTINA TABERNERO**
}

\section{LA SEÑORA CORNELIA Y QUIEN DA LUEGO, DA DOS VECES}

El presente trabajo pretende abordar, con perspectiva lingüística, la recreación teatral de La señora Cornelia que Tirso de Molina llevó a cabo en Quien da luego, da dos veces ${ }^{2}$, tema, por otra parte, que ya distintos autores han tratado desde la teoría o la historia literarias ${ }^{3}$. Cierto que la orientación que se escoge en estas páginas presenta puntos de encuentro ${ }^{4}$ con el estudio literario, en tanto

* Esta publicación se enmarca en el Proyecto de Investigación Fundamental «Edición crítica del teatro completo de Tirso de Molina. Tercera fase» (FFI2010-18619/FILO), subvencionado por el Ministerio de Ciencia e Innovación de España.

** GRISO. Universidad de Navarra.

1. Utilizo la siguiente edición de La señora Cornelia: Cervantes 2000: 481-520.

Para la obra de Tirso he cotejado el texto de Cotarelo (Molina, Tirso de (1907). «Quien da luego, da dos veces», Comedias de Tirso de Molina, ed. E. Cotarelo y Mori, tomo 3, Nueva Biblioteca de Autores españoles. Madrid: Bailly Bailliere e hijos, pp. 542-567) con el manuscrito conservado en la Biblioteca Nacional (mss. 15948), el mismo que sirve de base a aquel para su edición de la NBAE. No encuentro discrepancias entre ambos textos que afecten a este trabajo.

Para la numeración de los versos empleo la copia digital de la Biblioteca virtual Miguel de Cervantes disponible en < http://bib.cervantesvirtual.com/servlet/SirveObras/89140621093481695465679/ p0000001.htm\#I 2 >.

Me referiré a partir de este momento a las dos obras mediante siglas: LSC para La señora Cornelia y $Q D L$ para Quien da luego, da dos veces.

2. Para los datos bibliográficos sobre esta obra, ver Jurado, 2005: 224, y Vaiopoulos, 2009: 106; en esta última se ofrece asismismo una revisión de las opiniones sobre la filiación de la comedia tirsiana.

3. Entre otros, Close, 2004; Jurado, 2005 y Vaiopoulos, 2009 y 2010.

4. De hecho, señala Kabatek que «algunos autores han visto en el concepto de TD [tradiciones discursivas] una especie de sinónimo de género, otros incluso han intentado relacionar la noción de 
hace referencia a la configuración de determinados moldes discursivos, o a la repercusión lingüística que provoca la estratificación del material narrativo en la comedia, manifestada en «una operación de traducción transemiótica, que conduce necesariamente a una serie de transformaciones "prácticas"» (Jurado, 2005: 7), pero no se ocupa de contenidos, temas o estructuras.

Antes bien, desde el análisis de dos tradiciones discursivas -novela y comedia-, con especial atención a los casos de selección léxica, se quiere llegar a conclusiones sobre el uso de la lengua en el siglo XVII y sobre cómo este y aquellas, las tradiciones, condicionan el cambio lingüístico.

El concepto de tradiciones discursivas ${ }^{5}$, desarrollado fundamentalmente por lingüistas alemanes ${ }^{6}$ a partir de la teoría propuesta por B. Schlieben-Lange $(1983)^{7}$, se ha definido como «la repetición de un texto o de una forma textual o de una manera particular de escribir o de hablar que adquiere valor de signo propio (por lo tanto es significable)» (Kabatek, 2005: 159). Este marco metodológico se presenta, pues, apropiado para establecer la comparación entre dos textos que, partiendo de una misma premisa temática y compartiendo momento sociohistórico, llegan a soluciones diferentes en virtud de los imperativos a que se ven obligados en la adaptación a dos moldes discursivos diferentes ${ }^{8}$. El proceso que se lleva a cabo en el cambio del discurso narrativo de La señora Cornelia al discurso teatral de Quien da luego... ha de ubicarse dentro de la intertextualidad ${ }^{9}$ como interferencia textual -«siempre que haya transformación de una TD, habrá interferencia» (Kabatek, 2005: 162)-, ampliación de la inter-

discurso contenida en el término TD con el concepto del discurso foucaultiano. Las contribuciones que desde diferentes ángulos han intentado dar cuenta de la tradición de los textos, desde el género de Bakhtin hasta las diferentes tipologías textuales de la actualidad pasando por ideas como la «etimología del texto» de Lausberg, no son incompatibles con la concepción de TD, todo lo contrario, y es una de las tareas de la investigación actual relacionar los estudios de las TD con las diferentes herencias de las distintas escuelas» (Kabatek, 2008b: 9).

5. «Para dar cuenta de la tradición de los textos en un sentido amplio, preferimos, en vez de hablar de tipos, de géneros, de formas, estilos, etc., textuales, hablar de Tradiciones discursivas. Wulf Oesterreicher habla de las Tradiciones discursivas como de (17) moldes normativos convencionalizados que guían la transmisión de un sentido mediante elementos lingüísticos tanto en su producción como en su recepción» (Kabatek, 2007: 338).

6. Kabatek, 2007 y 2008b; Oesterreicher, 2011; Koch, 2008: 53-87.

En los últimos años se han publicado además varias obras de conjunto en el marco metodológico de las tradiciones discursivas: Oesterreicher, Stoll y Wesch, 1998; Jacob y Kabatek, 2001; Kabatek, 2008a; Castillo y Pons, 2011.

7. Esta teoría hunde su raíz asimismo en las distinciones coserianas de los niveles del lenguaje, fundamentales en la consideración del cambio lingüístico (ver Coseriu 1973). Ver para los antecedentes de esta metodología la introducción a Kabatek, 2008b.

8. Al tratar de las adaptaciones teatrales de las novelas ejemplares cervantinas, A. Close concluye: «Con estas salvedades, me parece que la diferencia fundamental entre los dos géneros es la que va de la comedia propiamente dicha a un género narrativo intermedio entre la comedia y la épica» (Close, 2004: 38).

9. Que se ha planteado como una de las condiciones de la textura en el modelo de Beaugrande y Dressler (ver Pons, 2008: 199). 
ferencia lingüistica, $\mathrm{y}$, en particular ha de enlazarse con la idea de la retextualización o refacción textual ${ }^{10}$.

En este sentido, las páginas que siguen permitirán, por un lado, adquirir constancia del condicionamiento que un determinado tipo discursivo impone sobre el léxico empleado por los autores como una de las estrategias que forma parte de la construcción textual, y, por otro lado, comprobar de qué modo este mismo condicionamiento ayuda a la difusión de unos términos sobre otros $y$, por ende, contribuye a los procesos de sustitución léxica y de desviación semántica que forman parte del cambio lingüístico. Es decir, el uso de unos lexemas concretos ha de venir en parte determinado por la base textual que los acoge y esta determinación provoca a su vez la progresión de estos términos en detrimento de otros, sin que esta afirmación implique en ningún caso el olvido de factores sociohistóricos.

Atendamos, pues, a nuestro objeto de estudio. Novela cortesana y comedia palatina han sido las denominaciones bajo las que se han considerado, respectivamente, la narración cervantina y la comedia tirsiana. Se ha señalado igualmente la coincidencia temática entre ambos textos - «caso de honor resuelto gracias a la cortesía y a la generosidad» (Vaiopoulos, 2009: 107) ${ }^{11}$-, la similitud en la tipología de los personajes principales, en el enredo y en la ambientación, y la existencia de escenas homológas ${ }^{12}$. Estamos, por tanto, ante una transposición que se ve supeditada al empleo de los elementos que convierten la narración en comedia, de manera que el diferente modo de enunciación propio de cada género obliga indefectiblemente a la presencia de unos determinados recursos lingüísticos, que sitúan el texto dentro de su tradición discursiva.

El análisis de los textos desde las tradiciones discursivas se ha centrado fundamentalmente en la reflexión sintáctica, que representa evidentemente el ámbito de mayor repercusión en la estructuración del discurso. En este sentido, las dos obras estudiadas en este trabajo responden a los patrones establecidos para la novela o la comedia en la lengua del siglo XVII y obedecen a las características que constituyen los modos de enunciación diégetico o mimético. La estructura dialógica, definida esencialmente por la interacción y

10. Para entender la retextualización o la refacción textual ha de partirse de la textualización como expresión de contenidos mentales por medio de palabras, de modo que «la refacción textual de un discurso supone un proceso de retextualización, que implica manipulación y adaptación de la lengua o el contenido de un texto a un nuevo propósito, a un nuevo proyecto, a un nuevo escenario social o histórico» (Pons, 2008: 201).

11. Cf. también para la comparación temática entre las dos obras García Martín, 1978: 140-145.

12. «Tirso conserva perfectamente las relaciones entre los personajes: los protagonistas de $L a$ señora Cornelia vuelven a aparecer en la comedia con algunos cambios que intensifican la conflictividad, sobre todo sentimental, y la diferencia sustancial entre los dos sistemas de personajes consiste casi exclusivamente en el «número» de papeles, que aumenta para completar el reparto de la comedia y para facilitar una cantidad de damas suficientes al juego sentimental y a la saturación de las posibilidades matrimoniales» (Vaiopoulos, 2009: 108-109).

Ver para todos estos aspectos, especialmente para la comparación en detalle del material diegético, Vaiopoulos, 2009: 107. 
los turnos de palabra, frente a la estructura narrativa, cuyos elementos fundamentales vienen representados por el acontecimiento y la categoría temporal, se plasman a través de cambios relacionados principalmente con la polifonía textual y con la deíxis exofórica obligada por el aquí y el ahora del discurso teatral. La estructura dialógica de este condiciona la transformación sintáctica del texto en la medida en que predomina el discurso directo sobre el indirecto, a pesar de que las novelas cervantinas hubieran sido calificadas en su tiempo de «comedias en prosa» por su acentuado dramatismo, a imitación de la novela italiana del momento ${ }^{13}$.

Sin embargo, más que en la disposición sintáctica de los discursos me interesa centrarme en el modo en que la selección léxica de cada uno de los autores ha de estar condicionada, al lado de preferencias estilísticas, por el tono y la orientación que un mismo contenido requiere según moldes discursivos diferentes.

Vienen a coincidir estas afirmaciones con algunas cuestiones sobre las que los especialistas de la literatura áurea han llamado sobradamente la atención desde hace ya algunos años cuando han clamado por una correcta interpretación de los textos en los que es necesario, por una parte, deslindar formas distintas dentro de un mismo género (cf. Arellano, 1999: 7) ${ }^{14}$ y atender, por otra, a las convenciones propias de este:

De modo que, en consecuencia, no todas las comedias son iguales, ni son susceptibles de interpretaciones parejas ni resultan válidas lecturas que orillen, por ignorancia o adrede, las convenciones que las rigen y los códigos que las estructuran. (Florit, 2000: 66) ${ }^{15}$

Con el propósito mencionado analizaré diferencias y coincidencias léxicas de especial relevancia que se observan en ambos textos. En unos casos se enfrentarán situaciones paralelas y en otras ocasiones se hará referencia a los distintos términos empleados, al diferente grado de uso de una misma voz e incluso a las preferencias por la repetición literal como procedimiento unificador del discurso frente a la reiteración sinonímica.

13. Ver para estas consideraciones, Close, 2004: 22.

14. Arellano se refiere en concreto a la Comedia áurea. Otros especialistas han avalado asimismo esta afirmación; este es el caso de. F. Florit (2000: 66), quien se hace eco de las palabras de I. Arellano al mostrar, a través del análisis de El vergonzoso en palacio, de Tirso, la conciencia por parte del autor de un tipo de comedia determinado: la comedia palatina.

15. Florit recoge afirmaciones de Arellano en este mismo sentido (cf. Arellano, 1999: 7). 


\section{COINCIDENCIAS TEMÁTICAS Y DISCREPANCIAS LÉXICAS}

\subsection{Responsabilidad de los hermanos}

Entre los hechos paralelos en las dos obras figura la situación de orfandad de los Bentibolli y de los Gonzaga y la responsabilidad de los hermanos Lorenzo y Marco Antonio- de cuidar de la honra de sus hermanas -Cornelia y Margarita-. Mientras Cornelia queda bajo la guarda y amparo de Lorenzo Bentibolli (p. 483), Margarita «está bajo la cautela/ de Marco Antonio Gonzaga» (p. 297). Autoridades, que marca cautela como voz «puramente latina», define este término en su sentido recto como 'el acto prudente con que se preveen los accidentes que pueden sobrevenir en daño y perjuicio propio o ajeno'16; en cambio, guarda es lo mismo que 'custodia y diligencia que se pone en el cuidado de alguna cosa' (DA ${ }^{17}$, s.v) y amparo, 'la protección, el favor, el socorro y ayuda que se da a otro' (DA, s.v).

La cautela completa su sentido con las palabras de Luis referidas a Marco Antonio:

hermano vuestro, que os cela

como padre, $y$ es bien lo haga,

que el cuerdo siempre recela. (QDL, I, vv. 173-175),

que añaden el 'celo' al 'cuidado' (cela) y a aquel la 'sospecha' (recela) (DA: s.vv. zelar y rezelar); sin embargo, aunque el ocultamiento físico se encuentre también presente en Lorenzo Bentibolli -«que ni ella se dejaba ver ni su hermano consentía que la viesen» (LSC: 483)-, el hermano de Cornelia guarda a esta con solicitud -«Era el recato de Cornelia tanto y la solicitud de su hermano tanta en guardarla» (LSC: 483)- y califica de la misma manera su propio comportamiento: «ser yo honrado y ella muchacha y hermosa me hacían andar solícito en guardarla» (p. 498). A la solicitud y guarda corresponden las prevenciones y diligencias-«pero todas mis prevenciones $y$ diligencias» (LSC: 498)- que Lorenzo tomará para proteger a Cornelia, precedidas del recato de esta, hipónimo de diligencia -«ni guardas, ni recatos, ni honrosas amonestaciones, ni otra humana diligencia fue bastante para estorbar el juntarnos» (LSC: 493)-, y de su apartamiento voluntario de la vista ajena, como se confirma más adelante:

16. Covarrubias habla únicamente del 'engaño que uno hace a otro ingeniosamente, usando de términos ambiguos y de palabras dudosas y equívocas', de donde resulta el cauteloso, 'el recatado que no se deja engañar y se previene con bastantes diligencias en cuanto le es lícito; otras veces se toma en mala parte' (Covarrubias: s.v.).

17. Esta será la referencia empleada para el Diccionario de Autoridades [1726-1739], de la Real Academia Española.

Ofreceré las definiciones de Covarrubias y Autoridades siempre que interese contraponer los rasgos sémicos entre los términos empleados en la novela y en la comedia. 
De pequeña edad quedé huérfana de padre y madre, en poder de mi hermano, el cual, desde niña, puso en mi guarda el recato mismo, puesto que más confiaba de mi honrada condición que de la solicitud que ponía en guardarme. (LSC: 493).

Frente al recato de Cornelia, al que su propio hermano hará referencia más adelante cuando habla de una «doncella temerosa y recatada», como se verá más abajo, en $Q D L$, Marco Antonio pregunta al viejo jardinero

¿Tú sabes si fue liviana

con el Príncipe mi hermana? ( $Q D L$, I, vv. 714-715),

para declarar exaltadamente versos más adelante:

Basta,

que mi enemigo mayor

ha triunfado de mi honor

y que no es mi hermana casta. ( $Q D L, \mathrm{I}, \mathrm{vv}$. 758-761)

Incluso Margarita califica su actitud en iguales términos: «no es posible, que ha sentido/ mi hermano mi liviandad» ( $Q D L$, II: vv. 68-69). Es liviano el 'inconsistente o deshonesto' (DA: s.v.), o 'el hombre inconstante y que fácilmente se muda' (Cov. ${ }^{18}$ : s.v.), que encuentra su contrario en el comportamiento casto 'puro, continente, opuesto al deshonesto, y dado al vicio de la luxuria' (Cov.: s.v.).

Además de liviana, Margarita es loca -'por semejanza se llama el sugeto de poco juicio y assiento, disparatado e imprudente' (DA: s.v.):

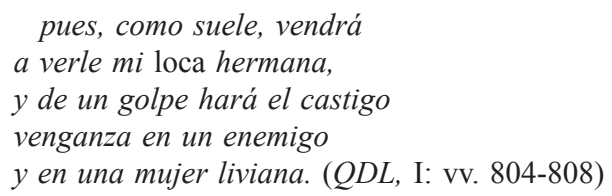

Este adjetivo califica a su vez el comportamiento de varios de los protagonistas de la comedia: lo dice Margarita de sí misma ( estoy loca ${ }^{19}$ ), Carlos sobre su estado («loco, pues, de haberme visto...»), doña Elena («loco estoy»), Carlos refiriéndose a Marco Antonio («villano, loco, atrevido») o sobre el grado de su desgracia (“¿cómo no me he vuelto loco?»), don Luis sobre su persona («loco estoy de pena y celos») o en respuesta al gracioso Calvete («calla, loco»), que también recibe el mismo calificativo por parte de doña

18. Indicaré de este modo las consultas en el Tesoro de la lengua castellana o española [1611], de S. de Covarrubias.

19. Omito las referencias al número de páginas de la novela o a los versos de la comedia cuando la acumulación de ejemplos o su brevedad así lo aconsejan, con el fin de evitar excesivas interferencias en el texto. 
Elena ( $«$ o sois loco»). Del mismo modo es loco el amor de doña Elena por don Luis («amor loco: yo por vos y vos por otro»). A veces alterna loco con la expresión sin seso, dirigida, por ejemplo, de Marco Antonio a Carlos: «Que vienes sin seso creo».

Sin embargo, en LSC no se habla de comportamientos livianos sino de voluntad arrojada - «pero todas mis prevenciones y diligencias las ha defraudado la voluntad arrojada de mi hermana Cornelia» (p. 498)- de una doncella temerosa y recatada:

\begin{abstract}
Lo que creo es que él se atuvo a lo que se atienen los poderosos que quieren atropellar una doncella temerosa y recatada, poniéndole a la vista el dulce nombre de esposo, haciéndola creer que por ciertos respetos no se desposa luego; mentiras aparentes de verdades. (LSC: 499).
\end{abstract}

Sin embargo, para Marco Antonio $(Q D L)$ Margarita es vil, en el sentido de la última acepción de Autoridades -'la persona, que falta a la confianza, u correspondencia a ella' (DA, s.v.)-; incluso el hijo es mal nacido y Carlos, fementido:

\author{
Si mi ventura le alcanza, \\ mi muerto honor resucita, \\ a un tiempo tres vidas quita, \\ la de Carlos fementido, \\ la del hijo mal nacido \\ y la vil de Margarita. (QDL, II: vv. 666-671).
}

Tanto Cornelia como Margarita se ven amenazadas por el deseo de venganza de sus respectivos hermanos: a Cornelia Lorenzo le va a quitar la vida ( Sin duda debe de haber sabido que estoy aquí, y viene a quitarme la vida», LSC: 497), en tanto que Marco Antonio «dar esta noche intenta/ fin a mi vida y su afrenta» (QDL, I: vv. 70-71), donde la expresión empleada viene bien para la contraposición entre las posesiones de los dos sustantivos. En ambos casos se hace hincapié en arrebatar aquello que pertenece a otro y que es propio de cada uno, la vida.

Por otra parte, ante esta amenaza Margarita pide piedad al cielo ( $;$ iTened, cielos, piedad/ de mi vida!», QDL, II: vv. 72-73) y Cornelia se acoge al amparo de sus guardianes («;Socorro, señores, y amparo!», LSC: 497).

\title{
2.2. Los presuntos engañadores
}

En las reacciones del duque de Ferrara y del Príncipe de Parma, el primero, Alfonso, hace referencia a «la fe que di»-'sinifica también la palabra o promessa que se da de hacer alguna cosa, como de juramento o de pleito homenaje, de suerte que si no se cumple redunda en descrédito de que la 
dio' (DA: s.v. ${ }^{20}$-, mientras que el segundo, Carlos, habla de cumplir una obligación -«Que una vez fortalecido/ y en mi Estado, verá amor,/ a pesar de toda mi Italia,/ cuál cumplí mi obligación» (QDL, I: vv. 619-622)-, es decir, 'lo que uno debe cumplir según su calidad y oficio' (Cov.: s.v.), la de hacer público su amor a Margarita.

\subsection{El carácter español}

Otro de los puntos comunes entre los dos textos es la referencia reiterada al carácter español, cifrado, según Cornelia, en la cortesía («por la cortesía que siempre suele reinar en los de vuestra nación, os suplico, señor español», LSC: 489) o en la gentileza ("Aquí veo tus prendas, aquí me veo sin ti encerrada y en poder que, a no saber que es de gentiles hombres españoles, el temor de perder mi honestidad me hubiera quitado la vida», LSC: 490). La cortesía puede reunir desde la 'cortesanía, agrado, afabilidad y modo de proceder urbano y atento', hasta el 'buen tratamiento, blandura, apacibilidad y agasajo en el modo de tratar con otro' (DA: s.v. cortesía). Sin embargo, los gentiles hombres lo son por su aspecto (Cov., s.v. gentiles) o por la nobleza de nacimiento (DA: s.v. gentil).

Aunque también en Tirso se habla de la cortesía española («Pero ¿qué hazañas no ha hecho la cortesía española?», pregunta don Diego, QDL, II: vv. 410-411) y es virtud apreciable («Príncipe, la cortesíal puede más que los agravios», sentencia Marco Antonio, QDL, II: vv. 818-819), los españoles destacan especialmente por el valor, la piedad y la nobleza ( Gracias al cielo que goza/ tan noble amparo mi miedo./ Si el valor y la piedad/ nobles atributos son/ que ensalzan vuestra nación», QDL, II: vv. 108-113; «[...] yo vengo a ser/vuestro paje, y lo que os pido,/ por la nobleza española/ con que vuestro nombre honráis/ es que a nadie descubráis/ quién soy [...]», QDL, II: vv. 895-900). También son conocidos los españoles por la acción valerosa a la que sobran las palabras:

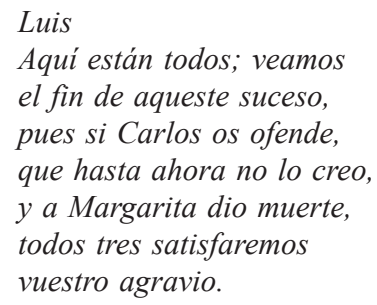

Diego

Vida y honra

20. Autoridades incluye asimismo varias acepciones de la expresión dar fe, tomada, según el diccionario académico, de la lengua jurídica. 
por [vos] perderá Don Diego.

Marco

Sois españoles, que basta. ( $Q D L$, III: vv. 759-767).

Las referencias al valor, léxicamente representadas por este u otros designadores, se prodigan por la comedia tirsiana como virtud masculina que transita la frontera entre la nobleza y el arrojo, en un momento sociohistórico en que la primera presupone la segunda: «Gocéis, Carlos valeroso,/ con Parma el dichoso empleo/ de Margarita» (QDL, III: vv. 851-853), apostrofa Luis al Príncipe de Parma, o saluda Marco Antonio a don Luis: "¿Qué hay, Don Luis valeroso?» ( $Q D L$, III: v. 323); también don Diego atribuye esta cualidad a don Luis -«Con eso das testimonio,/ don Luis, de tu valor» (QDL, II: vv. 741-742)-, o el propio don Luis a sí mismo -«que podrá más el valor de don Luis de Toledo» (QDL, II: v. 406)- o Carlos ensalzando su virtud -«que le deis fe a mi valor» ( $Q D L$, III: v. 238)-. En cambio, el valor en las mujeres -es el caso de Margarita o de doña Elena- parece restringido a la cualidad noble o de pura estimación, que nada tiene que ver con el arrojo:

\section{Luis}

Noble soy, perded el miedo.

Margarita

Siendo mujer, ¿cómo puedo

si la licencia española

conozco y su inclinación?

Luis

Pues, ¿qué tiene?

Margarita

Es tan extraña, que, según nuestra opinión, nunca echó de ver España

si era calva la ocasión.

Luis

Cortedad es [el] perdella cuando nunca usaron della manchando vuestro valor. ( $Q D L, \mathrm{I}$ : vv. 8-18)

en la que a veces coinciden con los hombres:

Diego

¿Qué teméis, señora mía?

Margarita

Alguna descortesía. 
Diego

Gente somos de valor.

Margarita

Pues mostradle en no impedir

mi camino. ( $Q D L$, II: vv. 94-98).

En $L S C$, hallamos referencias al valor, de acuerdo con la coincidencia temporal e histórica, aunque en número menor y, lo que es más importante, mucho más diversificadas desde el punto de vista léxico; es decir, son varios los lexemas que se emplean para cubrir el dominio significativo mencionado. La mayoría de ellos se reconocen también en Tirso pero, al contrario que en la comedia, donde predomina abrumadoramente la forma sustantiva, la novela hace uso asimismo de otras categorías: «valeroso padre», referido al duque de Ferrara en boca del cura que cobija a Cornelia, "con lo que valgo y puedo», en palabras de Alfonso, el duque, similares a las de Lorenzo, «os ofrezco cuanto tengo, puedo y valgo»; como "honradísimo y valiente caballero» define el narrador a Lorenzo Bentibolli, al «valor de Cornelia» se refiere el duque - «a quien pensaba dejar burlada por acudir al valor de Cornelia» (LSC: 518)-, de valeroso califica el narrador el corazón de don Juan de Gamboa: «Oyendo $y$ viendo lo cual don Juan, llevado de su valeroso corazón, en dos brincos se puso al lado, y metiendo mano a la espada» (LSC: 485), actitud que en otro momento es «ligereza y valor estraño»: "Don Juan creyó que le habían muerto, y con ligereza y valor estraño se puso delante de todos» (p. 485). Cornelia hace referencia a su honra vencida como «la roca de la valerosa $y$ honrada presunción mía»; los hombres que socorren al duque tras la refriega son "gentes de prendas y de gran valor». El valor de la nobleza y el arrojo también se aprecian en Cervantes, aunque de distinta manera por las dos diferencias mencionadas, a saber, el grado de reiteración de una misma forma y la selección de la categoría sustantiva.

\subsection{La deshonra y el engaño de las damas}

Este hecho, que desencadena la trama, se transmite con lexemas diferentes en cada uno de los discursos. Cuando don Juan de Gamboa hace de medianero, como él se denomina, en el litigio entre el duque de Ferrara y Lorenzo Bentibolli, habla de una queja -'se llama tambien el sentimiento que se tiene de algun agravio, injuria, menosprecio u desaire' (DA: s.v.)- frente a la injuria -'palabra u acción de que a otro se le sigue afrenta o agravio' (DA: s.v.)-, que resuena constantemente en los personajes de Tirso:

- Señor, Lorenzo Bentibolli, que alli veis, tiene una queja de vos no pequeña. (LSC: 507) 


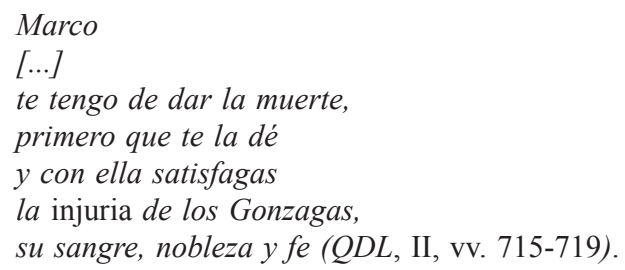

Don Juan $(L S C)$ señala ante el duque la falta cometida como engaño y deshonra: «Dice que habrá cuatro noches que le sacastes a su hermana, la señora Cornelia, de casa de una prima suya, y que le habéis engañado y deshonrado» (LSC: 501).

En la comedia se trata de un agravio reparable únicamente con la muerte, como se comprueba en los versos anteriores, mientras que en la novela debe existir satisfacción aunque no ha de ser obligadamente tan extrema: «quiere saber de vos qué satisfación le pensáis hacer, para que él vea lo que le conviene» (LSC: 507).

Evidentemente, está en el papel del intermediario, según las indicaciones de Margarita, obtener la paz entre ambos:
[...] [Cornelia a don Juan] ¿Quiero yo tan poco al duque o a mi hermano que de cualquiera de los dos no tema las desgracias y las sienta en el alma? [...] [Don Juan a Cornelia] Y entended, señora Cornelia, que la salud y contento de vuestro hermano y el del duque llevo puestos en las niñas de mis ojos; yo miraré por ellos, como por ellas. (LSC: 501).

Injurias y agravios, que necesitan venganza, son, en cambio, los términos que Tirso selecciona para referise al suceso principal y a otros secundarios. Injuria recibe la familia de Margarita por parte de los duques de Parma ( $[\ldots]$ en quien vive/ vuestra injuria y mi afición», $Q D L$, I: vv. 462-463; «mas, sí, que la sangre clama/ de mi muerto padre y llama/ a la venganza la injuria» ( $Q D L$, I: vv. 774-776); «el agresor de mi injuria»), doña Elena por parte de don Luis ("hasta que pueda vengar/la injuria que me hace España», $Q D L$, II: vv. 495-496), los Gonzaga de los de Parma ( «y con ella satisfagas/ la injuria de los Gonzagas», QDL, II: vv. 717-719; «vengue su injuria en los dos», «la nobleza en pechos sabios/ olvidos de injurias cría», QDL, II: vv. 816-817).

En $L S C$ se comprueba, por el contrario, una única sentencia con el término injuria, cuyo efecto repetino se desaconseja:

Mirad cuándo queréis que sea nuestra partida, y sería mejor que fuese luego, porque el hierro se ha de labrar mientras estuviere encendido, y el ardor de la cólera acrecienta el ánimo, y la injuria reciente despierta la venganza. (LSC: 500)

De agravio habla doña Elena ( $Q D L)$ («traerá otra vez el agravio»), Marco ("del castigo más cruel/ que dio un agravio a un traidor», "satisfágase mi agravio», «no satisfizo mi agravio»), Carlos («satisfecho moriría,/ porque el 
agravio lo estél que a darme muerte os incita», QDL, II: vv. 809-811; "pueden más que los agravios/ la piedad que vive en ellos», QDL, II: vv. 785-786; «olvidados sus agravios», «mi pobreza y vuestro agravio», «no crece sobre agravios el amor»), don Luis («olviden agravios antiguos», «satisfaremos vuestro agravio»), Margarita («interrompan/ mis agravios el silencio»); el agravio se cura con la cortesía («la cortesía/ puede más que los agravios») y a veces se mezcla con el amor («agravios con amor»).

En contraste, en la novela cervantina son escasas las referencias al mismo suceso con este término: el duque («qué satisfacción puedo daros del agravio que os hice», LSC: 518), Lorenzo («no consintió que con su sangre sacase la mancha de mi agravio», LSC: 499; "y no he querido contar a nadie este agravio» LSC: 499), don Juan ("tomo a mi cargo la satisfación o venganza de vuestro agravio» LSC: 500), e incluso se habla de su inexistencia (tranquilizando a Cornelia don Juan -«donde no se os ha de hacer agravio alguno»- o don Antonio -«en parte estáis y en poder de quien no os dejará hacer el menor agravio del mundo»-, p. 497).

Del mismo modo, la venganza no forma parte apenas de la prosa cervantina y se ve semánticamente aminorada por los contextos de uso. Don Juan justifica la venganza en términos de satisfacción del agravio -«tomo a mi cargo la satisfacción o venganza de vuestro agravio» (LSC: 500)-; por otra parte, en esta misma conversación entre Lorenzo Bentibolli y don Juan, se presenta como elemento negativo, en una intervención citada líneas más arriba: «la injuria reciente despierta la venganza» (LSC: 500$)$.

Es lugar común y abundantemente reiterado, sin embargo, a lo largo de toda la comedia de Tirso, la forma sustantiva: en boca de Margarita - «la venganza en las mujeres/ es natural condición» (QDL, I: vv. 449-450)-, de Carlos - ¿no le daría perdón,/ a pesar de la venganza,/ que es de tiranos blasón?»(QDL, I: vv. 434-436), «jtomad venganza!» (a Margarita), "para tu venganza invoco», "el peligro y la ocasión/ que daba a vuestra venganza» (a Margarita) ( $Q D L$, I: vv. 528-529), «su venganza solicita» (en ambos casos por la supuesta muerte de Margarita), «venganza tan inaudita»-; en palabras de Marco Antonio -«mas, sí, que la sangre clama/ de mi muerto padre y llamal a la venganza la injuria» (QDL, I: vv. 774-776), "pues a la venganza cuadre muerte», "venganza en un enemigo», "Huyó el Príncipe traidor/ con mi hermana, y mi venganza,/ por tardar, no satisfizo/ mi agravio; mas ¿cuándo hizo/ cosa buena la tardanza?» (QDL, II: vv. 661-665).

Venganza se acompaña también en la comedia de voces pertenecientes a su misma familia léxica con predominio de la categoría verbal: «sed vos el vengador», "no comienzo a vengar a mi esposa», "vengue su injuria en los dos», "vengaos, que os hace traición», "vengarme podré», "hasta que pueda vengar/ la injuria que me hace España» (QDL, II: vv. 495-496), «nos ha vengado el cielo», «la vida que vengar quieres».

Por tanto, las preferencias cervantinas se inclinan por la variación léxica, aunque sea por razones estilísticas, en contraste con Tirso, que opta, como parte del mecanismo dramático, por la reiteración del mismo lexema. Señala- 
ré, a modo de ejemplo, el episodio en que se cuenta en cada una de las obras la entrada de la dama deshonrada en la posada del caballero español. En esta ocasión el autor de la novela habla de crédito frente a otros momentos en que se escoge el sustantivo honor, honra o el verbo deshonrar:

os suplico, señor español, que me saquéis destas calles y me llevéis a vuestra posada con la mayor priesa que pudiéredes, que allá, si gustáredes dello, sabréis el mal que llevo y quién soy, aunque sea a costa de mi crédito (LSC: 488),

elementos que incluso llegan a coordinarse: «o quizá imaginaría otras peores cosas que redundasen en perjuicio de su honra y del buen crédito de Cornelia» (p. 511).

En cambio, en las escenas en que se representa este suceso en $Q D L$ se echa mano del honor, de la honra y de sus derivados:

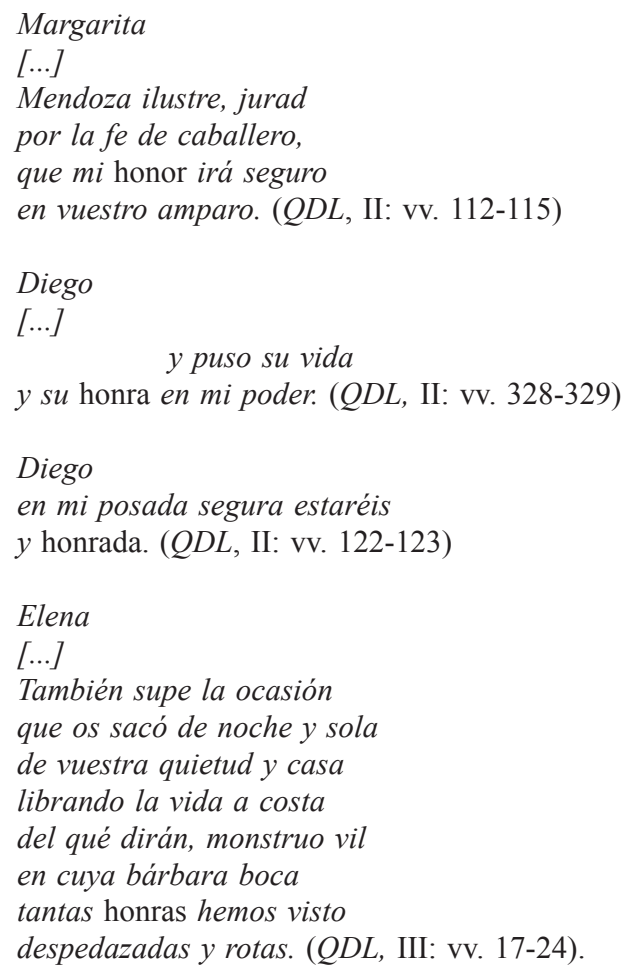

Aunque, como corresponde al tema y a la sociedad de la época, las familias léxicas de honor y de honra son constantes en el desarrollo de las dos obras, no interesa, sin embargo, en $Q D L$ la presencia de voces tales como honesto ${ }^{21}$,

21. Solo en un caso aparece el sintagma «nobleza y honestidad». 
honestidad o decoro ${ }^{22}$, vocablos que emplea con profusión Cervantes: «en silencio honesto y amoroso», "con el más honesto y puntual decoro», «por modos honestos y honrosos», «honestas y hermosas», «algunas honestas mocedades», «tan honestos pensamientos se malogren», «el temor de perder mi honestidad», "poder dar con honestidad de mamar a la criatura», «con más decoro se guardase el que a su honestidad se debía».

\subsection{Cornelia y Margarita}

En el conjunto de voces que sirven para la caracterización de las protagonistas, el autor de la novela emplea para referirse a Cornelia el campo asociativo de la 'pena', representado principalmente por la familia léxica de desdicha y de desgracia: " $i A y$, desdichada!», "desdichada de mí», "remediar desdichas», «mis desdichas serían mayores», «mi desdichada historia», «sabrá tener en silencio vuestras desgracias», "las dos tan ricas como desgraciadas prendas», «no tema las desgracias y las sienta en el alma», "a quien se la da el cielo para mayor desgracia». La imagen se completa con las continuas referencias al llanto en cualquiera de sus lexemas - «la doncella llorando», «amargamente lloraba», "estaba derramando hermosas lágrimas», «con la mano en la mejilla, derramando tiernas lágrimas», "replicó con lágrimas y ruegos»-, que atañen incluso a otros personajes -el duque y Lorenzo- en los que las lágrimas resultan menos esperables («añadiendo lágrimas a lágrimas», «ya no son menester lágrimas aqui sino júbilos y fiestas», «se le arrasaban los ojos de lágrimas»), como declara el narrador («pero consideraron que parecía flaqueza dar muestras con lágrimas de tanto sentimiento, las reprimieron y volvieron a encerrar en los ojos», LSC: 509). Tirso, por el contrario, prefiere designadores como injuria, agravio, deshonra, necesitados siempre de venganza, según se ha visto más arriba. Las lágrimas se descubren en pocas escenas: «suspiros y llantos», «ni sus celos ocasión de nuevos llantos».

\subsection{Mecanismos léxicos exclusivamente dramáticos}

Puede comprobarse por lo visto hasta el momento que la comedia, condicionada lingüísticamente por los usos dialógicos, echa mano de aquellas voces que, en una escala de gradación sémica, resulten menos neutras; dicho de otro modo, que provoquen la reacción tanto del alocutario activo (el interlocutor en la escena) como del pasivo (el receptor/espectador). Por tanto, Tirso obedece, como señalaba Florit para El vergonzoso en palacio (cf. §1), a la conciencia

22. Decoro se emplea polisémicamente en el texto: «se os guardará el decoro que vuestra presencia merece», "que aquel era el decoro más conveniente» 'honor, respeto, reverencia que se debe a alguna persona por su nacimiento o dignidad' (DA: s.v.). 
del tipo genérico en el que escribe, y es esta circunstancia la que lo lleva a preferir voces que caracterizan más marcadamente a sus personajes en extremos que provocan acciones más drásticas que las narrativas.

En consecuencia, el discurso teatral exige la presencia de términos de fuerte carga expresiva en virtud de su función y de su significado; a esta razón obedece el empleo de adjetivos cuyo significado denotativo implica defectos morales («el apetito villano persuade al pensamiento», «aquese pecho infame», «el Príncipe traidor», «injusto poseedor»), susceptibles de ser empleados como insultos en función conativa, plenamente característicos del lenguaje dialógico: ";Oh, infame!», " iVive Dios que has de morir, disimulado traidor!», «iAy, príncipe engañador!», " $i A h$, príncipe inclemente!», "jvete, necio!», "iAh, necio!», ";Calla, loco!, que no digo eso», "jvillano, acabemos ya!», ";traidor!», ";ah, tirano Marco Antonio!»; incluso en secuencias acumulativas: «jvillano, loco, atrevido!».

A estos usos se añaden los juramentos tan característicos del discurso oral de la época, que colaboran al dramatismo del parlamento, ya sea en su versión propia o en su deformación eufemística, cuya codificación, la de ambas, queda fuera de toda duda en la lengua aurisecular ${ }^{23}-« P a r$ Dios», «por Dios», «por vida vuestra», "pardiez», "iVive Dios!», "iVálgame Dios!», "jválgate el diablo!», «iJesús!», «ipesia a tal!», «vive Dios»-. Convienen aquí también las maldiciones - «mal haya»- y los lamentos o exaltaciones en la misma función: «iCielos!», «iAy, cielos!», "iAy, prenda mía!», "ique os voy a ver, cara prenda!», " $i A y$, prenda del alma hermosa!», «iAy, prenda mía!», « $i A y$, triste de mí!», "iAy de mí!», «iAy, industrias amorosas!», «iAy, sospechoso temor!».

Estos términos, sobre todo cuando se emplean como agresores verbales, no son adecuados, sin embargo, a la novela, excepto en las reproducciones en estilo directo. Aun en estas, que no escasean en el texto cervantino, no abundan los usos mencionados y en el conjunto de la novela no se hace uso apenas de adjetivos calificadores de defectos o vicios morales: «por mentirosos o embusteros», «traidores pueden poco», «no quiero ser descortés», "desatentada $y$ loca»; y escasas exclamaciones: «iAy, bien mío!», «iPecadora de mí!», "iAy, desdichada!», "iAy, sin ventura!», "jválame Dios!», "iAh, traidores, que sois muchos!», "ipor vida del señor don Juan!», "por vida mía», «jVálamos Dios!».

\section{COINCIDENCIAS TEMÁTICAS Y LÉXICAS}

Referidas las discrepancias entre los dos textos, han de anotarse algunas similitudes léxicas que aproximan las dos obras. Ambos discursos coinciden en

23. La literatura es pródiga en testimonios, que diversas documentaciones de la lengua común refrendan como producciones auténticas y no solo ficcionales. Cf. a este respecto Tabernero, 2012 y 2013 . 
el uso de un léxico caracterizador de la cronología a la que pertenecen con variaciones necesarias en su adaptación al tipo textual. De este modo sucede en el uso del $\operatorname{ceceo}^{24}$, que, según se trate de narración o comedia, toma forma verbal o interjectiva:

al pasar por una calle que tenía portales sustentados en mármoles oyó que de una puerta le ceceaban (LSC: 483)

Fabia

$\mathrm{Ce}$, ¿quién pasa?

¿Sois el Príncipe? Llegad. (QDL: 310)

Asimismo, algunas fórmulas consagradas en la lengua de la época varían de acuerdo con la necesidad discursiva:

Hacedme merced de decirme quién sois y vuestro nombre, para que yo sepa a quién tengo de mostrarme agradecida (LSC: 486).

Sepa yo a quién tanta merced debo (QDL: 324).

En otras ocasiones la coincidencia es casi absoluta, cuando no se plantean problemas provenientes de los condicionamientos que imponen las bases textuales. Igualmente saludables son, por ejemplo, los consejos que el ama de cría $(L S C)$ y doña Elena $(Q D L)$ ofrecen, cada una en su caso, a sus damas:

- ¿ ¿qué consejo me daríades, vos, amiga, que fuese saludable y que previniese la sobrestante desventura? (LSC: 504)

Margarita

Fuerza es que escoja

tus consejos saludables. (QDL, III, vv. 204-205).

La abundante documentación de este sintagma prueba su extensión en el uso literario de la época ${ }^{25}$.

También son comunes a los dos textos las referencias al temor, representadas en su designación por las familias léxicas de temor o de miedo. Sirven fundamentalmente para justificar la actitud de Cornelia -«el temor de perder mi honestidad», "con temor de peores sucesos», "por más que el temor me aflija en vuestra ausencia», "con tanto ahinco y tantas muestras de temor», «no tema las desgracias y las sienta en el alma», "salió la voz baja y temerosa», "Cornelia, temerosa de algún mal suceso», "atropellar una doncella temerosa y recatada», "mucho discurrís y mucho teméis», "habían echado la falta de Cornelia a su mucho miedo», «dad lugar entre tantos miedos a la esperanza», "el miedo que me había puesto la cuadrilla armada»-, y de

24. 'Se llama también el sonido semejante al de la ce, que se forma juntando los dientes, è hiriendo en ellos con la lengua: el qual sirve de seña para detener, llamar, ò hacer callar' (DA, s.v.).

25. En CORDE se registran 29 ocurrencias en 24 documentos del sintagma consejo(s) saludable(s) y 122 en 62 documentos de saludable(s) consejo(s) en el período comprendido entre 1500 y 1700. 
Margarita: «el temor me fuerza a huir», «temerosa de Marco Antonio salía» (don Luis hablando de Margarita), "El temor, que es adivino,/ revolvió las tristes hojas/ de mis desdichas, y en ellas/leyó mi ventura corta» (QDL, III: vv. 97-100), "Ya yo temí la mudanza/ de Carlos, que era forzosa,/ porque una mujer gozada/ es trato que anda de sobra» (QDL, III: vv. 101-104), "goza tan noble amparo mi miedo», "perded el miedo» (don Luis a Margarita), "con miedo os he oído», "¿Palabras miedo os han dado?» (don Diego a Margarita), "Celos, peligro y temor/ contra vos al arma tocan» (doña Elena a Margarita) ( $Q D L$, III: vv. 81-82); aunque también es sentimiento que albergan otros personajes, como Carlos: «sin duda puede el temor/ darme la pena presente», doña Elena: "Ay, sospechoso temor», "tuvo de vernos temor», «no tengas miedo» (a don Diego), Marco Antonio: «si es cuerdo el temor, es noble la confianza» (QDL, III: vv. 256-257), "el temor de mi pasado rigor» o Peynado: «es todo oídos el temor».

De otro lado, los términos pertenecientes al campo léxico de sosiego se observan en Cervantes y en Tirso, tanto en su forma nominal como verbal, esta última empleada como respuesta en interacción con otro personaje; sucede de igual manera con el uso de voces como confuso/a, confusión, confundido/ da. Sin embargo, Cervantes prefiere la construcción confuso y suspenso, o su variante femenina, y Tirso pone en dos ocasiones en boca de los personajes el vocablo enredo:

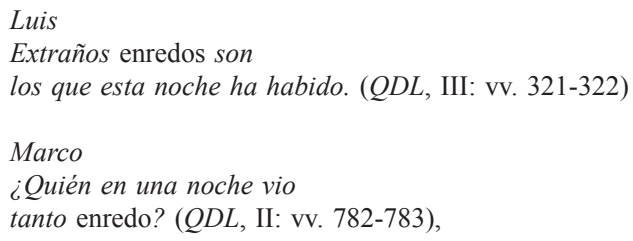

en intervenciones de falso diálogo, que suponen, como sucede habitualmente en el teatro, la interacción con el espectador.

\section{FINAL}

Resumiré ahora las razones por las que el diferente léxico seleccionado por cada uno de los autores para transmitir temas y contenidos idénticos ${ }^{26}$ obedece a la necesidad de construir dos discursos con finalidades distintas.

Se muestra en el análisis precedente, según creo, cómo la mayoría de los términos escogidos por el discurso narrativo se mueven, bien en su sentido recto o en el contextual, en un ámbito semántico de rasgos menos rotundos

26. «Tirso tiende a conservar los temas de la novela - cortesía, generosidad, amistad, fuerza del amor, visión de los españoles en el extranjero- y la trama centrada en la solución no violenta de un caso de honor» (Vaiopoulos, 2009: 124). 
en su expresividad que las voces escogidas en el discurso teatral: la guarda, el amparo, la solicitud, frente a la cautela, propiciada por el recelo (cf. \$2.1). Según se desprende de las definiciones lexicográficas, el 'cuidado' constituye la base sémica de los primeros términos y la 'previsión del hecho que se da por seguro' la del segundo.

Asimismo, el comportamiento deshonesto de las protagonistas merece calificaciones diferentes según los discursos y el punto de vista. La novela busca su justificación, destacando su recato y temor, sin mención explícita a su posible liviandad, aunque sepamos que existe ${ }^{27}$, en tanto que la Margarita de Tirso aparece calificada sin ambages de liviana, no casta, loca y vil, al tiempo que otros personajes, incluso el recién nacido, reciben adjetivaciones fuertemente expresivas -mal nacido, fementido.

En esta misma línea el discurso cervantino gira en torno a la perfección en las formas y en el comportamiento -cortesía, honestidad y decoro-, por encima de la rotundidad de las cualidades morales en el Mercedario -valor, nobleza, piedad, honra y honor- (cf. §2.3).

De igual modo, la queja ('sentimiento'cf. $\S \S 2.4,2.5$ ) del discurso narrativo como sentimiento de ofensa frente a la acción de la injuria y del agravio necesitados de venganza del molde teatral separan los dos repertorios léxicos, en la medida además en que la 'agresión' externa tirsiana se sustituye en Cervantes, de acuerdo con el sentimiento que implica la queja, por el elemento interno de la 'pena' con lexemas como desgracia, desdicha y sus derivados o con la presencia de las lágrimas (cf. §2.5).

Por otra parte, el discurso narrativo prefiere la variación léxica por identidad semántica, que permite destacar rasgos diferentes sobre un mismo hecho, como sucede en el caso de honra, honor y crédito, o en los distintos derivados de valor que se oponen a las reiteraciones literales del teatro. El uso de la recurrencia en este último caso viene provocado, de un lado, por la variación diafásica en la medida en que se trata de un procedimiento propio de la oralidad, en este momento, de la teatral, como modo de cohesión del discurso. De otro lado, la reiteración léxica intensifica la expresividad de los términos escogidos, recurso que conviene también a la teatralidad. Ambos elementos se unen a la especial fuerza de los significados y a la profusión de los insultos en función conativa, al lado de otras expresiones como los lamentos y juramentos (§2.6).

Finalmente, la comedia ha de hacer por fuerza referencia léxica al enredo, que la novela entendía como estado de los personajes confusos y suspensos $(\S 3)$.

En suma, con todas las salvedades que las preferencias estilísticas de cada uno de los autores pudieran ofrecer a las afirmaciones precedentes y aun existiendo puntos concomitantes $(\S 3)$, parece que la selección léxica diferente

27. La propia Cornelia dice de sí misma: «En resolución, a cabo de pocos días me sentí preñada, y antes que mis vestidos manifestasen mis libertades, por no darles otro nombre, me fingí enferma y malancólica» (LSC: 494). 
ofrece unas constantes que vienen justificadas por la adaptación a los distintos moldes discursivos: el efectismo teatral origina el uso de voces de mayor fuerza semántica que mantengan la atención en el espectador y que proporcionen, junto con otros elementos, los constituyentes esperables en la comedia áurea.

Al margen de las preferencias de autor, que podrían incluso resultar engañosas ante las posibles modificaciones introducidas por los editores de las distintas impresiones, el léxico de otras épocas interesa también a la diacronía por otra de las cuestiones que afecta al cambio lingüístico, a saber, la presencia o ausencia de una voz en virtud de su grado de difusión, y de su radio de uso sociocultural. Del mismo modo, la especial proliferación de algunos lexemas en la lengua común puede deberse a su empleo recurrente en las obras áureas, especialmente de aquellos términos escuchados con frecuencia en los corrales de comedias.

El condicionamiento que las tradiciones discursivas implican en los usos léxicos de una época determinada contribuye al triunfo de una serie de vocablos, que se irán perdiendo posiblemente en cuanto la recurrencia pierda su efectividad y el momento social supere los valores establecidos en los tiempos precedentes.

Por otra parte, las variaciones léxicas por equivalencia semántica pueden provocar, como está comúnmente admitido, cambios también semasiológicos que se reflejan en la desviación significativa de un término o en la adquisición de nuevos sentidos.

\section{BIBLIOGRAFÍA}

Arellano, Ignacio (1999). Convención y recepción. Estudios sobre el teatro del Siglo de Oro. Madrid: Gredos.

Castillo, Mónica y Lola Pons (eds.) (2011). «Así se van las lenguas variando». Nuevas tendencias en la investigación del cambio lingüístico en español. Bern/Berlin/Bruxelles/Frankfut am Main/New York/Oxford/Wien: Peter Lang.

Cervantes, Miguel de (2000). «La señora Cornelia», en Miguel de Cervantes, M., Novelas ejemplares, ed. J. García López. Barcelona: Crítica, pp. 481-520.

Close, Anthony (2004). «Cómo se deshace una novela para hacer una comedia», Cervantes y el IV Centenario del Quijote. Anuario de Estudios Cervantinos. 1, pp. 21-38.

Covarrubias, Sebastián de (2006). Tesoro de la lengua castellana o española [1611] (ed. integral e ilustrada de Ignacio Arellano y Rafael Zafra). Madrid/Frankfurt: Iberoamericana / Vervuert.

Coseriu, Eugenio (1973 [1958]). Sincronía, diacronía, historia. El problema del cambio lingüistico. Madrid: Gredos.

Florit, Francisco (2000). «El vergonzoso en palacio: arquetipo de un género», en Ignacio Arellano y Blanca Oteiza, Varia lección de Tirso de Molina. Actas del VIII seminario del Centro para la edición de clásicos españoles (Madrid, Casa de Velázquez, 5-6 de julio de 1999). Pamplona: Instituto de Estudios Tirsianos, pp. 65-83.

García Martín, Manuel (1978). «Dos modelos cervantinos en Tirso de Molina», Anales cervantinos. 17 , pp. 137-146. 
Jacob, Daniel y Kabatek, Johannes (eds.) (2001). Lengua medieval y tradiciones discursivas en la Península Ibérica. Descripción gramatical, pragmática histórica, metodologia. Frankfurt am Main/Madrid: Iberoamericana/Vervuert.

Jurado, Agapita (2005). Obras teatrales derivadas de novelas cervantinas (siglo XVII). Kassel: Reichenberger.

Kabatek, Johannes (2005). «Tradiciones discursivas y cambio lingüístico», Lexis. 29/2, pp. 151-177.

Kabatek, Johannes (2007). «Las tradiciones discursivas entre conservación e innovación», Rivista di filologia e letterature ispaniche. 10, pp. 331-348.

Kabatek, Johannes (ed.) (2008a). Sintaxis histórica del español y cambio lingüístico: Nuevas perspectivas desde las Tradiciones Discursivas. Frankfurt am Main/Madrid: Iberoamericana/Vervuert.

Kabatek, Johannes (2008b). «Introducción», en Johannes Kabatek (ed.), Sintaxis histórica del español y cambio lingüístico. Nuevas perspectivas desde las Tradiciones Discursivas. Madrid/ Frankfurt am Main: Iberoamericana/ Vervuert, pp. 7-16.

Koch, Peter (2008). «Tradiciones discursivas y cambio lingüístico: el ejemplo del tratamiento de vuestra merced en español», en Johannes Kabatek (ed.), Sintaxis histórica del español y cambio lingüístico. Nuevas perspectivas desde las Tradiciones Discursivas. Madrid/ Frankfurt am Main: Iberoamericana/ Vervuert, pp. 53-87

Molina, Tirso de (1907). «Quien da luego, da dos veces», Comedias de Tirso de Molina (ed. E. Cotarelo y Mori), Nueva Biblioteca de Autores Españoles. Madrid: Bailly Bailliere e hijos, tomo 3, pp. 542-567.

Molina, Tirso de (1982 [1952]). «Quien da luego, da dos veces», en Molina, Tirso de, Obras dramáticas completas (ed. Blanca de los Ríos). Madrid: Aguilar, tomo 3, pp. 287-338.

Oesterreicher, Wulf; Stoll, Eva y Andreas Wesch (eds.) (1998). Competencia escrita, tradiciones discursivas y variedades lingüisticas. Tübingen: Günter Narr Verlag.

Oesterreicher, Wulf (2011). «Conquistas metodológicas en la lingüística diacrónica actual. La historicidad del lenguaje: lenguas, variedades y tradiciones discursivas en el marco de una semiótica social», en Mónica Castillo y Lola Pons (eds.), «Así se van las lenguas variando» Nuevas tendencias en la investigación del cambio lingüístico en español. Bern/ Berlin/ Bruxelles/ Frankfut am Main/ New York/ Oxford/ Wien: Peter Lang, pp. 305-334

Pons, Lola (2008). «El peso de la tradición discursiva en un proceso de textualización: un ejemplo en la Edad Media castellana», en Johannes Kabatek (ed.), Sintaxis histórica del español y cambio lingüistico. Nuevas perspectivas desde las Tradiciones Discursivas. Madrid/ Frankfurt am Main: Iberoamericana/ Vervuert, pp. 197-224.

Real Academia Española (1979). Diccionario de Autoridades [1726-1739]. Madrid: Gredos, 3 vols.

Real Academia Española. Corpus diacrónico del español. Disponible en $<$ http://corpus. rae.es/cordenet.html>.

Tabernero, C. (2012). «Estudio de algunas voces injuriosas del español clásico», en Antoni Nomdedeu, Esther Forgas y María Bargalló (eds.), Avances de Lexicografía hispánica. Tarragona: Universitat Rovira i Virgili, pp. 495-508.

Tabernero, C. (2013). «Léxico injurioso y tipos de discurso en el Siglo de Oro», en C. Pérez-Salazar, C. Tabernero y J.M. Usunáriz (eds.), Los poderes de la palabra: el improperio en la cultura hispánica del Siglo de Oro. NewYork, Bern, Berlin, Bruxelles, Frankfurt am Main, Oxford, Wien: Peter Lang, pp. 257-275.

Vaiopoulos, Katerina (2009), «La versión teatral de La señora Cornelia de Cervantes», Hesperia. Anuario de filología hispánica. 12-1, pp. 105-125. 
Vaiopoulos, Katerina (2010). De la novela a la comedia: las Novelas ejemplares de Cervantes en el teatro del Siglo de Oro. Vigo: Academia Editorial del Hispanismo.

Recibido: 20 de enero de 2012

Aceptado: 19 de septiembre de 2012

\title{
Resumen
}

En este artículo se analiza el proceso de refacción textual o retextualización de la novela corta cervantina La señora Cornelia que Tirso de Molina llevó a cabo en su comedia Quien da luego, da dos veces. Partiendo del concepto de tradición discursiva como elemento significativo del cambio lingüístico, se estudia el modo en que un mismo contenido se plasma a través de selecciones léxicas diferentes o coincidentes en cada una de las obras mencionadas como consecuencia del proceso que implica el paso de los moldes narrativos a los teatrales. Las preferencias determinadas por el carácter diegético de la novela han de adaptarse en la comedia al discurso mimético.

Palabras clave: tradición discursiva; selección léxica; variación lingüística; Cervantes; Tirso; novela; comedia.

Title: From the Narrative to the Theatratical Discourse: Lexical Selection in Cervantes and Tirso

\begin{abstract}
This article analyzes the retextualization of La señora Cornelia, a Cervantes' novel, that was carried out by Tirso de Molina in his comedy Quien da luego, da dos veces. Based on the concept of discursive tradition as a significant element of linguistic change, this paper studies how the same content is expressed by different or coincident lexical selections in both works as a result of the adaptation of the narrative molds to the dramatic molds. The linguistic choices determined by the diegetic character of the novel must adapt to the mimetic discourse of the comedy.
\end{abstract}

Key words: discursive tradition; lexical selection; linguistic variation; Cervantes; Tirso; novel; comedy. 